\title{
Fish consumption and respiratory symptoms among young adults in a Norwegian community
}

\author{
Ø. Fluge, E. Omenaas, G.E. Eide, A. Gulsvik
}

Fish consumption and respiratory symptoms among young adults in a Norwegian community. Ø. Fluge, E. Omenaas, G.E. Eide, A. Gulsvik. (OERS Journals Ltd 1998.

ABSTRACT: The aim of this study was to investigate the relationship between dietary fish consumption and self-reported respiratory symptoms among young adults.

A random sample of 4,300 subjects, aged 20-44 yrs, living in Bergen, Norway, received a postal questionnaire on respiratory symptoms, of whom $80 \%$ responded. Mean fish consumption was assessed in a food-frequency questionnaire by asking how often the subject consumed units of fish $(150 \mathrm{~g})$ during the last year.

Average fish consumption was 1.8 units $^{\cdot}$ week $^{-1}$. Fish intake of $<1$ unit $^{\cdot}$ week $^{-1}$ was reported by $24 \%, 41 \%$ reported consumption of 1 unit $^{\cdot}$ week $^{-1}$ and $35 \%$ intake of $>1$ unit'week ${ }^{-1}$. A high fish intake was significantly associated with increasing age after adjusting for smoking. Adjusted for smoking habits, the prevalence of "cough at night" and "chest tightness" showed a decreasing trend with increasing fish consumption $(p<0.05)$, while such a trend for "wheeze" was demonstrated only in smokers $(p=0.008$ for interaction). In logistic regression models (adjusting for age, sex, body mass, smoking habits and occupational exposure) fish consumption (three categories) was not significantly associated with "wheeze", "chest tightness", "breathless at night" or "asthma attack", although the odds ratios (OR) were consistently less than 1 (except for "asthma attack"). Fish consumption was of borderline significance as a protective factor of "cough at night", $O R=0.86$ (95\% confidence interval: $0.76-0.97)$ but in stratified analyses only in smokers. Subjects reporting very high levels of fish consumption (>14 units'week ${ }^{-1}$ ) did not have lower prevalences of respiratory symptoms.

In conclusion, among young Norwegian adults, with a relatively low prevalence of asthma and an overall high fish intake, fish consumption was not a significant predictor of four out of five respiratory symptoms.

Eur Respir J 1998; 12: 336-340.
Dept of Thoracic Medicine, University of Bergen, Bergen, Norway.

Correspondence: $\emptyset$. Fluge

Dept of Thoracic Medicine

Haukeland University Hospital

N-5021 Bergen

Norway

Fax: 4755975149

Keywords: Asthma

dietary habits

fish

population survey

respiratory symptoms

Received: October 301996

Accepted after revision April 181998

Supported by the Norwegian Research Fund for Asthma and Allergy and the Norwegian Research Council.
The $\omega-3$ polyunsaturated fatty acids of fish, primarily eicosapentaenoic acid (EPA) and docosahexaenoic acid (DHA), act as competitive inhibitors of arachidonic acid metabolism, thereby reducing the amount of active inflammatory mediators such as prostaglandins and leukotrienes from the cyclooxygenase and the lipoxygenase enzyme systems [1]. During the last decade, inflammation has increasingly been recognized as a major aspect of bronchial asthma and the leukotrienes generated from metabolism of arachidonic acid have a potent bronchoconstriction effect [2]. A study of dietary supplementation with fish oil lipids in patients with mild asthma did not improve clinical performance or symptom scores, but inhibition of leukotriene $\mathrm{B}_{4}$ generation could be demonstrated [3]. Aspects of the relationship between dietary fish oil consumption and airways obstruction have been discussed [4] and the role of fish intake in the occurrence of bronchial asthma and asthma-like symptoms remains unclear.

The aim of the present study was to investigate the relationship between dietary fish consumption and respiratory symptoms, among young adults of a Norwegian community with an overall high fish intake.
Subjects and methods

\section{Sample}

This cross-sectional study, in the city of Bergen, Norway, was performed as part of the European Community Respiratory Health Survey [5]. A random sample of 4,300 subjects, aged 20-44 yrs, of a survey population of 82,227 subjects in that age category were sent a postal questionnaire on October 1, 1991. Those not returning the questionnaire received a second and, if there was still no response, a third questionnaire, after 3 and 8 weeks, respectively. Subjects not returning the questionnaire after three letters were classed as nonresponders. The reasons for nonresponse were: moved out of the study area $(2 \%)$, unknown new address after moving (1\%) and unknown (17\%). A total of 3,450 subjects $(80 \%)$ responded to the postal questionnaire. The response rate increased with increasing age and was $77 \%$ among those aged 20-24 yrs and $82 \%$ among those aged 40-44 yrs. Among the responders 51\% were female. The mean age was 31 yrs in both males and 
females. The study was approved by the Regional Committee of Medical Research Ethics, University of Bergen.

\section{Questionnaire}

Dietary habits were assessed by a semiquantitative foodfrequency questionnaire by asking: "How often, on average during the last year, did you consume the following nutrients?". The unit for fish was $150 \mathrm{~g}$. The answers were given in nine consumption categories (never or less than $1 \cdot$ month $^{-1}, 1-3 \cdot$ month $^{-1}, 1 \cdot$ week $^{-1}, 2-4 \cdot$ week $^{-1}$, 5-6. week $^{-1}$, $1 \cdot$ day $^{-1}, 2-3 \cdot$ day $^{-1}, 4-5 \cdot$ day $^{-1}$, $>6 \cdot$ day $\left.^{-1}\right)$. The questionnaire was originally developed by Channing Laboratory, Harvard Medical School, and has documented acceptable reproducibility and validity [6]. Eight other dietary items were also assessed.

The following five symptoms, experienced by the subject during the last 12 months, were analysed: "Have you had wheezing or whistling in your chest at any time in the last 12 months?" ("wheeze"); "Have you woken up with a feeling of tightness in your chest at any time in the last 12 months?" ("chest tightness"); "Have you been woken by an attack of shortness of breath at any time in the last 12 months?" ("breathless at night"); "Have you been woken by an attack of coughing at any time in the last 12 months?" ("cough at night"); "Have you had an attack of asthma in the last 12 months?" ("asthma attack") [7].

Never-smokers were subjects who had never smoked daily. Exsmokers were subjects who had smoked daily and given it up. Smokers were those who smoked daily at the time of the study. The amount of lifetime smoking was assessed as pack-yrs. This was arrived at by using the duration of smoking in years multiplied by the number of cigarettes smoked per day and divided by 20 [8].

Occupational exposure was assessed by asking: "In your occupation, have you worked with or been exposed to mineral- or metal-dust in the last 12 months?" (asbestos, stone dust, rock dust, sandblasting, rockwool, glasswool, paint pigments with chromium, cement dust, textile or tannic dye colours with chromium, dust from nickel in electronic products, dust from cadmium alloys) and the answers were coded into four exposure categories (never, every month or less, every week, every day) ("occupational exposure"). The body mass index $\left(\mathrm{kg} \cdot \mathrm{m}^{-2}\right)$ was calculated from self-reported weight $(\mathrm{kg})$ and height $(\mathrm{m})$.

\section{Statistical analyses}

The proportions of missing data in the responders were low for respiratory symptoms $(<1 \%)$, fish intake $(1.3 \%)$ and smoking habits (3\%). It was somewhat higher for occupational mineral- or metal-dust exposure (17\%), thus reducing the power of the multivariate analyses when including this variable.

The fish consumption variable was recoded from the observed nine categories to a three-valued score with an approximately comparable number of subjects on each score-value, i.e. $1:<1$ unit $(150 \mathrm{~g}) \cdot$ week $^{-1}, 2: 1$ unit·week-1, and 3: $>1$ unit.week ${ }^{-1}$. Statistical analyses were also performed with two categories of fish intake: $<1$ unit.week-1 and Š1 unit week $^{-1}$. Dose-response relationships between fish intake (three-valued score) and age, sex, body mass, pack-years, occupational exposure and the five respiratory symptoms, respectively, were analysed adjusted for smoking categories by means of analysis of covariance for the continuous variables and logistic regression for the dichotomous variables. Separate multivariate logistic regression analyses were performed with each of the respiratory symptoms as the dependent variable. These analyses were carried out with the covariates age, sex, body mass, "occupational exposure" (four exposure levels), smoking habits and fish forced into the model. In logistic regression analyses, fish intake was analysed as a three-valued score, thereby estimating a possible dose-response effect. Multivariate analyses were also performed when excluding "occupational exposure" from the model. Interaction terms were made for pack-years based on the categories of smoking habits. All variables were treated as continuous in the multivariate logistic regression model. A p-value $<0.05$ was regarded as significant. All analyses were carried out using SPSS-Win version 6.1 (SPSS Inc, Chicago, IL, USA).

\section{Results}

\section{Fish consumption}

The average fish consumption per subject was 1.8 units. week $^{-1}$ (range 0-42 units). Eight-hundred and twenty-four subjects $(24 \%)$ consumed $<1$ unit $\cdot$ week $^{-1}, 1,377$ subjects (41\%) 1 unit-week ${ }^{-1}$ and 1,203 subjects $(35 \%)>1$ unitweek ${ }^{-1}$. Thirty-one subjects reported an average consumption of $>14$ units.week ${ }^{-1}(2,100 \mathrm{~g})$. Fish consumption increased with increasing age in smokers, exsmokers and never-smokers. Sex and body mass did not vary significantly with fish intake (table 1).

The prevalence of current smoking decreased with increasing fish intake: 52,46 and $40 \%$ in those consuming $<1,1$ and $>1$ unit fish $\cdot$ week $^{-1}$, respectively $(\mathrm{p}<0.001)$. However, the number of pack years did not vary significantly with the three categories of fish consumption. The distribution of "occupational exposure" (at least once a week during the last year) did not vary significantly with fish intake (table 1).

\section{Respiratory symptoms}

The crude prevalences of respiratory symptoms were: "wheeze" 25\%, "cough at night" 26\%, "chest tightness" $12 \%$, "breathless at night" 5\% and "asthma attack" $3 \%$.

The prevalence rates of respiratory symptoms by smoking habits and fish consumption are shown in table 1 . The crude rates of "wheeze", "cough at night" and "chest tightness" varied with the three categories of fish intake. When adjusted for smoking habits, the prevalences of "cough at night" and "chest tightness" showed a decreasing trend with increasing fish consumption $(\mathrm{p}<0.05)$, while such a trend for "wheeze" was demonstrated only in smokers ( $p=0.008$ for interaction). For "breathless at night" there was a borderline significant interaction between the threevalued fish score and smoking habits $(\mathrm{p}=0.053)$, indicating decreasing trends in exsmokers and current smokers but not in never-smokers (table 1). The prevalence of "asthma attack" did not vary significantly with fish intake. 
Table 1. - Age, body mass index and pack-years (mean \pm so) and percentages of female, occupational exposure and five respiratory symptoms according to fish consumption and smoking habits

\begin{tabular}{|c|c|c|c|c|c|}
\hline \multirow[b]{2}{*}{ Dependent variables } & \multicolumn{3}{|c|}{ Fish intake units.week-1* } & \multicolumn{2}{|c|}{ Significance probabilities ${ }^{\dagger}$} \\
\hline & $\begin{array}{c}<1 \\
(n=824)\end{array}$ & $\begin{array}{c}1 \\
(n=1377)\end{array}$ & $\begin{array}{c}>1 \\
(n=1203)\end{array}$ & Fish intake & $\begin{array}{c}\text { Interaction term } \\
\text { fish } \times \text { smoking habits }\end{array}$ \\
\hline \multicolumn{6}{|l|}{ Age yrs } \\
\hline Never-smokers & $28 \pm 6$ & $31 \pm 7$ & $32 \pm 7$ & & \\
\hline Exsmokers & $30 \pm 7$ & $34 \pm 7$ & $34 \pm 7$ & & \\
\hline Smokers & $29 \pm 6$ & $32 \pm 7$ & $33 \pm 7$ & & \\
\hline Total & $29 \pm 6$ & $32 \pm 7$ & $32 \pm 7$ & $<0.001 \quad(<0.001)$ & $0.548(0.887)$ \\
\hline Sex female, $\%$ & 49 & 52 & 49 & $0.249(0.622)$ & $0.985(0.897)$ \\
\hline Body mass index $\mathrm{kg} \cdot \mathrm{m}^{-2}$ & $23 \pm 3$ & $23 \pm 3$ & $23 \pm 3$ & $0.189(0.930)$ & $0.388(0.740)$ \\
\hline \multicolumn{6}{|l|}{ Pack-yrs } \\
\hline Exsmokers & $7 \pm 8$ & $8 \pm 8$ & $7 \pm 6$ & & \\
\hline Smokers & $11 \pm 9$ & $10 \pm 8$ & $10 \pm 7$ & & \\
\hline Total & $10 \pm 8$ & $10 \pm 8$ & $9 \pm 7$ & $0.773(0.47)$ & $0.455(0.904)$ \\
\hline \multicolumn{6}{|l|}{ Occupational exposure } \\
\hline Never-smokers & 9 & 8 & 7 & & \\
\hline Exsmokers & 8 & 7 & 8 & & \\
\hline Smokers & 14 & 12 & 12 & & \\
\hline Total & 11 & 9 & 9 & $0.396(0.277)$ & $0.962(0.850)$ \\
\hline \multicolumn{6}{|l|}{ Wheeze \% } \\
\hline Never-smokers & 13 & 9 & 14 & & \\
\hline Exsmokers & 15 & 11 & 18 & & \\
\hline Smokers & 48 & 36 & 37 & & \\
\hline Total & 31 & 22 & 24 & $<0.001(0.071)$ & $0.065(0.008)$ \\
\hline \multicolumn{6}{|l|}{ Cough at night $\%$} \\
\hline Never-smokers & 21 & 22 & 22 & & \\
\hline Exsmokers & 23 & 29 & 17 & & \\
\hline Smokers & 37 & 30 & 29 & & \\
\hline Total & 29 & 27 & 24 & $0.052(0.016)$ & $0.015(0.094)$ \\
\hline \multicolumn{6}{|l|}{ Chest tightness \% } \\
\hline Never-smokers & 7 & 7 & 8 & & \\
\hline Exsmokers & 16 & 11 & 8 & & \\
\hline Smokers & 19 & 14 & 14 & & \\
\hline Total & 15 & 11 & 11 & $0.021(0.022)$ & $0.197(0.048)$ \\
\hline \multicolumn{6}{|l|}{ Breathless at night $\%$} \\
\hline Never-smokers & 2 & 4 & 4 & & \\
\hline Exsmokers & 8 & 6 & 4 & & \\
\hline Smokers & 8 & 5 & 6 & & \\
\hline Total & 6 & 5 & 5 & $0.491(0.409)$ & $0.036(0.053)$ \\
\hline \multicolumn{6}{|l|}{ Asthma attack \% } \\
\hline Never-smokers & 2 & 3 & 3 & & \\
\hline Exsmokers & 5 & 2 & 4 & & \\
\hline Smokers & 2 & 3 & 5 & & \\
\hline Total & 3 & 3 & 4 & $0.205(0.149)$ & $0.306(0.485)$ \\
\hline
\end{tabular}

*: units of $150 \mathrm{~g}$. : significance probabilities from two-way analysis of variance, using a general linear model, for continuous dependent variables (age, body mass and pack-years). For dichotomous dependent variables (respiratory symptoms, sex, occupational exposure) logistic regression analyses (backwards, likelihood ratio test) were performed using fish intake (three valued score) and smoking habits (defined as a categorical predictor variable) in the models. Analyses were performed with fish intake coded as a categorical variable (factor) and as a covariate variable (continuous), thereby estimating a possible trend. Analyses were also performed both with and without the interaction term included in the models. The p-values for trends are given in parenthesis.

In separate analyses for never-smokers none of the respiratory symptoms decreased with increasing fish intake.

Subjects with a very high consumption of fish, $\breve{S} 2$ units $(\sim 300 \mathrm{~g}) \cdot$ day $^{-1}(\mathrm{n}=31,58 \%$ males, $45 \%$ smokers $)$, reported a higher prevalence of "chest tightness" than responders consuming less fish (23 versus $11 \%, \mathrm{p}=0.04)$. In this group, there were no significant differences in the prevalence of "wheeze", "cough at night", "breathless at night" or "asthma attack".

\section{Multivariate logistic regression analyses}

Adjusted odds ratios (OR) for respiratory symptoms by different predictor variables, in logistic regression models, are shown in table 2. After adjustments (for age, sex, body mass, "occupational exposure" and smoking habits/packyears), fish consumption (three levels) was significantly associated with "cough at night" ( $\mathrm{OR}=0.87,95 \%$ confidence intervals (CI): 0.76-0.97). Fish consumption was a significant predictor of neither "wheeze", "breathless at night", "chest tightness" nor "asthma attack". Table 2 also shows the adjusted OR for fish intake (in three and two consumption categories) as a predictor variable of the five respiratory symptoms and the effect of excluding "occupational exposure" is demonstrated. When "occupational exposure" was excluded from the model and fish intake divided into two categories, fish consumption was significantly related to "wheeze" (OR=0.79, 95\% CI: 0.650.96 ), but in stratified analyses only in smokers. 
Table 2. - Adjusted odds ratios (OR) with 95\% confidence intervals (Cl) for fish consumption and possible confounding predictor variables in logistic regression models

\begin{tabular}{|c|c|c|c|c|c|c|c|c|c|c|}
\hline \multirow[b]{2}{*}{ Predictor variables } & \multicolumn{2}{|c|}{ Wheeze } & \multicolumn{2}{|c|}{ Cough at night } & \multicolumn{2}{|c|}{ Breathless at night } & \multicolumn{2}{|c|}{ Chest tightness } & \multicolumn{2}{|c|}{ Asthma attack } \\
\hline & OR & $95 \% \mathrm{CI}$ & OR & $95 \% \mathrm{CI}$ & $\mathrm{OR}$ & $95 \% \mathrm{CI}$ & $\overline{\mathrm{OR}}$ & $95 \% \mathrm{CI}$ & OR & $95 \% \mathrm{CI}$ \\
\hline Fish, three levels* $(n=2570)$ & 0.98 & $0.86-$ & 0.86 & 0.76 & 0.95 & $0.74-1.22$ & 0.94 & 0.79 & 1.20 & $0.88-1.65$ \\
\hline Fish, two levels ${ }^{\dagger} \quad(n=2570)$ & 0.81 & $0.64-1.01$ & 0.80 & $0.65-0.99$ & 0.92 & $0.59-1.43$ & 0.91 & $0.68-1.22$ & 1.11 & $0.63-1.95$ \\
\hline Fish, three levels $\quad(n=3185)$ & 0.97 & $0.86-1.09$ & 0.91 & $0.82-1.01$ & 0.93 & $0.75-1.15$ & 0.94 & $0.81-1.08$ & 1.26 & $0.96-1.66$ \\
\hline Fish, two levels $\# \quad(n=3185)$ & 0.79 & $0.65-0.96$ & 0.89 & $0.74-1.08$ & 0.85 & $0.59-1.24$ & 0.86 & $0.67-1.09$ & 1.25 & $0.76-2.06$ \\
\hline Confounders§ & & & & & & & & & & \\
\hline se of $10 \mathrm{yrs}$ & .63 & $0.52-0.75$ & 0.77 & $0.65-0.90$ & 0.92 & $0.67-1.28$ & 0.58 & $0.46-0.74$ & 0.83 & $0.56-1.24$ \\
\hline e, $1=$ female) & 1.04 & $0.84-1.29$ & 2.30 & $1.87-$ & 1.79 & 1.18 & 1.79 & 1.34 & 1.29 & $0.78-2.13$ \\
\hline $\begin{array}{l}\text { Body mass index, increase } \\
\text { of } 5 \mathrm{~kg} \cdot \mathrm{m}^{-2}\end{array}$ & 1.31 & $1.10-1.56$ & 1.13 & $0.96-1.33$ & 1.47 & $1.10-1.98$ & 1.31 & $1.06-1.63$ & 1.27 & $0.86-1.88$ \\
\hline Occupational exposure & .21 & $1.07-1.36$ & 1.29 & $1.15-1.46$ & 1.27 & $1.02-1.59$ & 1.44 & $1.25-1.67$ & 0.91 & $0.64-1.29$ \\
\hline$=$ no, $1=$ yes) & 1.23 & $0.82-1.84$ & 0.96 & $0.69-1.35$ & 1.72 & 0.93 & 1.57 & $0.99-2.47$ & 1.01 & $0.45-2.25$ \\
\hline $\operatorname{Smoker}(0=$ no, $1=$ yes $)$ & 2.81 & $2.08-3.80$ & 1.08 & $0.82-1.43$ & 1.06 & $0.59-1.91$ & 1.25 & $0.85-1.85$ & 1.10 & $0.54-2.24$ \\
\hline $\begin{array}{l}\text { Pack-yrs, exsmokers, } \\
\text { increase of } 10\end{array}$ & 1.26 & $0.93-1.69$ & 1.22 & $0.92-1.60$ & 1.10 & $0.70-1.72$ & 1.28 & $0.91-1.79$ & 1.27 & $0.73-2.21$ \\
\hline $\begin{array}{l}\text { Pack-yrs, smokers, } \\
\text { increase of } 10\end{array}$ & 1.82 & $1.49-2.22$ & 1.46 & $1.20-1.76$ & 1.25 & $0.87-1.78$ & 1.66 & $1.30-2.11$ & 1.11 & $0.68-1.80$ \\
\hline
\end{tabular}

All five respiratory symptoms (dependent variables) were reported as experienced during the last 12 months. Results from separate analyses with fish intake in three and in two consumption categories are given and the effects of excluding "occupational exposure" from the logistic regression models are shown. *: fish (unit $150 \mathrm{~g})$, three levels, 1 : <1 week $^{-1}(\mathrm{n}=824), 2: 1 \cdot$ week $^{-1}(\mathrm{n}=1377), 3$ : $>1 \cdot$ week $^{-1}(\mathrm{n}=1203)$; : fish, two levels; 0: <1·week ${ }^{-1}(\mathrm{n}=824), 1: \mathrm{S} 1 \cdot$ week $^{-1}(\mathrm{n}=2580)$; : fish, three levels, "occupational exposure" excluded from the logistic regression model; \#: fish, two levels, "occupational exposure" excluded from the logistic regression model; §: OR for confounding variables given when fish coded in three levels and "occupational exposure" included in the model ( $\mathrm{n}=2570)$; $\$$ occupational exposure to inhaled mineral or metal dust, four levels, 0: never, 1: each month, 2: each week, 3: each working day.

In smokers (all covariates included) fish intake (three categories) was significantly related to "cough at night" (OR=0.77, 95\% CI: 0.65-0.92), but not to "wheeze", "breathless at night", "chest tightness" or "asthma attack". In exsmokers, fish consumption was only significantly associated with a low prevalence of "chest tightness" (OR= 0.62, 95\% CI: 0.42-0.91). In never-smokers, fish consumption was not significantly associated with any of the five respiratory symptoms mentioned.

\section{Discussion}

This study did not support the hypothesis that low fish consumption is cross-sectionally associated with asthmalike respiratory symptoms among young adults. However, as demonstrated in table 2, the OR for fish intake were consistently less than 1 (except for "asthma attack"). Thus, a minor protective effect of fish intake, present in a very large study population, cannot be excluded. Adjusted OR for fish intake as a predictor variable of respiratory symptoms showed a minor, but significant protective effect only of self-reported "cough at night" in smokers. In logistic regression analyses fish intake was only an independent predictor for "wheeze" when "occupational exposure" was excluded from the model and fish intake was coded in two categories. Subjects with a very high intake of fish ( $\breve{S} 2$ units. day $^{-1}$ ) reported a higher prevalence rate of "chest tightness", along with a tendency towards a somewhat higher prevalence of "wheeze", "cough at night", "breathless at night" and "asthma attack".

A high consumption of fish was associated with neversmoking. Other dietary constituents were not included in the multivariate model as these factors are known to be intercorrelated. Fish consumption as a predictor variable of the five respiratory symptoms analysed must therefore be interpreted with caution, in that fish intake may be a proxy for other dietary factors not included in the present analyses or registered in the questionnaire. In this study population, the average intake of fish was 1.8 unit.week $^{-1}$, without specifying the kind of fish consumed. This is in accordance with previous estimates of fish consumption in Norway [9]. This is considered to be a high intake of fish in a general population. In previous studies addressing fish consumption and respiratory symptoms, however, the mean fish intake per week was reported as $140 \mathrm{~g}$ [10] and 1.9 serving sizes of $85-142 \mathrm{~g}(=161-270 \mathrm{~g})$ [11], which is considerably lower than in the present study.

The random sample examined should be representative of the study population, although the percentage of males was higher among nonresponders than responders (61 versus 49\%). Both the questionnaire on respiratory symptoms [12] and the semiquantitative food-frequency questionnaire [6] have been validated. A recent study comparing a self-administered food-frequency questionnaire, as well as an interview-administered questionnaire with a 7-day food recording, reported good validity when using the former method to estimate nutrient intake [13].

The confounding variables of age, sex, body mass, smoking habits and "occupational exposure" have been taken into account to estimate the true effect of fish consumption on asthma-like symptoms. Smoking habits are a main risk factor of respiratory symptoms. "Occupational exposure" was a significant predictor variable of "whe-eze" when including all subjects in logistic regression analyses as well as in a stratified analysis in neversmokers. "Occupational exposure" was significantly related to "cough at night", especially in smokers and never-smokers. Even though the distribution of "occupational exposure" (at least once weekly) did not vary significantly across the three categories of fish intake in a univariate analysis (table 1), the observed differences in prevalence rates of "occupational exposure" may have an 
effect in multivariate logistic regression analyses. The minor changes in the adjusted OR for fish intake as predictors of "wheeze" or "cough at night", including or excluding "oc-cupational exposure" from the model, are interpreted as an argument in favour of including this confounding variable. However, owing to a relatively high proportion of missing data for "occupational exposure", the inclusion of this variable will reduce the power of the multivariate analyses.

Significant associations between fish consumption and respiratory symptoms have been reported in some crosssectional studies. A high fish intake was associated with a lower prevalence of self-reported bronchitis and wheezing [14] and with a higher forced expiratory volume in one second [15]. SHARP et al. [16] suggested that fish intake may have a protective role against smoking-related deficits in lung function. A study addressing the relation between dietary intake of polyunsaturated fatty acids and self-reported symptoms of chronic bronchitis, physiciandiagnosed emphysema or spirometrically detected chronic obstructive pulmonary disease (COPD), in current or exsmokers, found the intake to be inversely related to the risk of COPD in a dose-dependent fashion [11]. However, the population samples in these cross-sectional studies were adults with a mean age higher than 50 yrs and "occupational exposure" was not adjusted for, although some included variables of socioeconomic status and educational level.

TROIS et al. [17] reported no association between fish consumption and risk of developing asthma over a $10 \mathrm{yr}$ period. In another longitudinal study assessing the relationship between diet and 25-yr incidence of chronic nonspecific lung diseases among middle-aged males in the Netherlands, no association was found between dietary fish consumption (average $140 \mathrm{~g} \cdot \mathrm{week}^{-1}$ ) and incidence of lung disease [10]. An experimental study in 17 atopic asthmatics given 10 weeks of dietary supplementation with fish oil lipids showed no effects on the clinical severity of asthma, symptom scores or bronchodilatory drug usage [3]. Similarly, in 25 never-smoking pollen-sensitive asthmatic subjects given dietary supplementation of eicosapentaenoic acid over the pollen season (6-month period) no effects were found on bronchial reactivity, respiratory symptoms, diurnal variability in peak expiratory flow or use of medication compared with placebo (olive oil) [18]. A recent study among Australian children, investigating the association between fish consumption and asthma (defined as recent "wheeze" and airway hyperresponsiveness) and also specifying the kind of fish intake, concluded that oily fish ( $>2 \%$ fat) may protect against childhood asthma [19].

In conclusion, among young adults on the west coast of Norway, with a high level of fish intake, fish consumption was not significantly associated with self-reported "wheeze", "chest tightness", "breathless at night" or "asthma attack". A high consumption of fish may have a minor protective effect on self-reported "cough at night". However, the odds ratios for fish intake as a predictor variable were consistently less than 1 (except for "asthma attack"), although not significant. If fish intake was protective against respiratory symptoms, this might be expected in a population with a low prevalence of asthma [7] and an overall high fish intake. Thus, a minor protective effect of fish consumption on respiratory symptoms cannot be excluded.

\section{References}

1. Holtzmann MJ. Arachidonic acid metabolism. Implications of biological chemistry for lung function and disease. Am Rev Respir Dis 1991; 143: 188-203.

2. Weiss JW, Drazen JM, Coles N, et al. Bronchoconstrictor effects of leukotriene C in humans. Science 1982; 216: 196-198.

3. Arm JP, Horton CE, Spur BW, Mencia-Huerta JM, Lee TH. The effects of dietary supplementation with fish oil lipids on the airways response to inhaled allergen in bronchial asthma. Am Rev Respir Dis 1989; 139: 1395-1400.

4. Britton J. Dietary fish oil and airways obstruction. Thorax 1995; 50: 511-515.

5. Burney PGJ, Luczynska C, Chinn S, Jarvis D. The European Community Respiratory Health Survey. Eur Respir J 1994; 7: 954-960.

6. Willett WC, Sampson L, Stampfer MJ, et al. Reproducibility and validity of a semiquantitative food frequency questionnaire. Am J Epidemiol 1985; 122: 51-65.

7. European Community Respiratory Health Survey. Variations in the prevalence of respiratory symptoms, selfreported asthma attacks, and use of asthma medication in the European Community Respiratory Health Survey (ECRHS). Eur Respir J 1996; 9: 687-695.

8. Omenaas E, Bakke P, Eide GE, Elsayed S, Gulsvik A. Total serum IgE and FEV 1 by respiratory symptoms and obstructive lung disease in adults of a Norwegian community. Clin Exp Allergy 1995; 25: 682-689.

9. Central Bureau of Statistics. Estimates of food consumption 1989-91. Official statistics of Norway NOS C 65 (in Norwegian). Oslo, Central Bureau of Statistics, 1993.

10. Miedema I, Feskens EJM, Heederik D, Kromhout D. Dietary determinants of long-term incidence of chronic nonspecific lung disease. The Zutphen Study. Am $J$ Epidemiol 1993; 138: 37-45.

11. Shahar E, Folsom AR, Melnick SL, et al. Dietary $\omega-3$ poly-unsaturated fatty acids and smoking-related chronic ob-structive lung disease. N Engl J Med 1994; 331: 228 233.

12. Burney PGJ, Laitinen LA, Perdrizet $\mathrm{S}$, et al. Validity and repeatability of the IUATLD (1984) Bronchial Symptoms Questionnaire: an international comparison. Eur Respir $J$ 1989; 2: 940-945.

13. Jain M, Howe GR, Rohan T. Dietary assessment in epidemiology: comparison of a food frequency and a diet history questionnaire with a 7-day food record. Am J Epidemiol 1996; 143: 953-960.

14. Schwartz J, Weiss ST. Dietary factors and their relation to respiratory symptoms. Am J Epidemiol 1990; 132: 67-76.

15. Schwartz J, Weiss ST. The relationship of dietary fish intake to level of pulmonary function in the first National Health and Nutrition Survey (NHANES I). Eur Respir J 1994; 7: 1821-1824.

16. Sharp DS, Rodriguez BL, Shahar E, Hwang LJ, Burchfiel CM. Fish consumption may limit the damage of smoking on the lung. Am J Respir Crit Care Med 1994; 150: 983987.

17. Troisi RJ, Willett WC, Weiss ST, Trichopoulos D, Rosner B, Speizer FE. A prospective study of diet and adultonset asthma. Am J Respir Crit Care Med 1995; 151: 1401-1408. 
18. Thien FCK, Mencia-Huerta JM, Lee TH. Dietary fish oil effects on seasonal hay fever and asthma in pollen-sensitive subjects. Am Rev Respir Dis 1993; 147: 1138-1143.
19. Hodge L, Salome CM, Peat JK, Haby MM, Xuan W, Woolcock AJ. Consumption of oily fish and childhood asthma risk. Med J Aust 1996; 164: 137-140. 